\title{
Chronic opioid use following surgery for head and neck cancer patients undergoing free flap reconstruction
}

\author{
Ashley Hinther ${ }^{1}$, Alysha Rasool', Steven C. Nakoneshny ${ }^{2}$, Shamir P. Chandarana ${ }^{1,2}$, Robert Hart ${ }^{1,2}$, \\ T. Wayne Matthews ${ }^{1,2}$ and Joseph C. Dort ${ }^{1,2^{*}}$ (i)
}

\begin{abstract}
Background: Physician opioid-prescribing patterns have significant impacts on the current opioid crisis. Patients who use opioids in the postoperative period are at risk of developing chronic postoperative opioid use. This study determined the rate of chronic postoperative opioid use among head and neck cancer patients undergoing primary surgery with free-flap reconstruction. Additionally, this study identified major risk factors associated with the development of chronic postoperative opioid use.

Methods: A retrospective chart review was performed for all adults (age $\geq 18$ years) undergoing primary head and neck surgical resection with free-flap reconstruction between January 2008 and December 2015. Patients were identified from a prospectively collected database, Otobase ${ }^{\mathrm{TM}}$. Data from the provincial drug insurance program were used to capture drug dispensing information to determine chronic opioid use at 3- and 12-months postoperatively. Data extracted from Otobase ${ }^{\mathrm{TM}}$ included patient demographics, social habits, clinical stage, pathological stage, type of surgery, and adjuvant treatment.

Results: The total cohort was comprised of 212 patients. Chronic opioid use at 3- and 12-months postoperatively was observed in 136 (64\%) and 116 (55\%) patients, respectively. Of the 212 patients, 85 patients (40\%) were identified as preoperative opioid users and 127 were opioid naïve (60\%). Of the 85 patients who were preoperative opioid users, 70 (82\%) and 63 (77\%) patients continued to use opioids 3-and 12-months postoperatively, respectively. The proportion of opioid-naïve patients who were using opioids at 3-and 12-months postoperatively was 52\% (66 patients) and 42\% (53 patients), respectively. Identified risk factors included preoperative opioid use, prior tobacco use, advanced pathologic T-stage, and adjuvant treatment.
\end{abstract}

Conclusions: Among head and neck cancer patients that have undergone major resection with free-flap reconstruction, the prevalence of chronic postoperative opioid users was considerable. Identified risk factors included preoperative opioid use, prior tobacco use, tumor stage, and adjuvant treatment.

Keywords: Head and neck surgery, Postoperative pain, Opioids, Postoperative opioid use

\footnotetext{
* Correspondence: jdort@ucalgary.ca

'Department of Surgery, Section of Otolaryngology- Head and Neck Surgery,

Cumming School of Medicine, University of Calgary, HRIC 2A02 3280

Hospital Dr NW, Calgary, Alberta T2N 4Z6, Canada

${ }^{2}$ Ohlson Research Initiative, Arnie Charbonneau Cancer Institute, Cumming

School of Medicine, University of Calgary, Calgary, Alberta, Canada
}

(c) The Author(s). 2021 Open Access This article is licensed under a Creative Commons Attribution 4.0 International License, which permits use, sharing, adaptation, distribution and reproduction in any medium or format, as long as you give appropriate credit to the original author(s) and the source, provide a link to the Creative Commons licence, and indicate if changes were made. The images or other third party material in this article are included in the article's Creative Commons licence, unless indicated otherwise in a credit line to the material. If material is not included in the article's Creative Commons licence and your intended use is not permitted by statutory regulation or exceeds the permitted use, you will need to obtain permission directly from the copyright holder. To view a copy of this licence, visit http://creativecommons.org/licenses/by/4.0/. The Creative Commons Public Domain Dedication waiver (http://creativecommons.org/publicdomain/zero/1.0/) applies to the data made available in this article, unless otherwise stated in a credit line to the data. 


\section{Background}

An opioid-associated public health emergency exists, in part, because of a dramatic rise in opioid-prescriptions and opioid-related deaths [1]. Within the past year, the number of deaths in Canada from accidental overdose secondary to opioids has increased by greater than $40 \%$. Opioids are now the most frequently prescribed drug class in the United States [2, 3]. Deaths from prescription opioids in the United States quadrupled between 2000 and 2014, and are correlated with a concurrent 4fold increase in the quantity of opioids dispensed [3]. Most opioid abusers receive opioids through a diversion of an appropriately-obtained drug; 1 in 4 cancer patients admit to losing or sharing prescribed opioids [1, 4, 5]. Furthermore, there is a direct relationship between the number of opioid overdoses within a community and the quantity of prescription drugs dispensed [6].

The origin of the opioid epidemic is partly secondary to an effort put forth by the American Pain Society in the 1990s for better in-hospital pain management $[7,8]$. The labeling of pain as a "fifth vital sign" resulted in the marketing of opioids as a superior alternative to other, non-addictive analgesics. Opioid medications provide an effective means for managing acute postoperative pain; however, opioids are associated with significant sideeffects including respiratory depression, constipation, nausea and vomiting, and impaired mobilization $[9,10]$. Postoperative opioid use has also been linked to the subsequent development of opioid dependency; therefore, the postoperative period represents a challenging situation in optimizing pain control while minimizing the risks of chronic opioid use [11, 12].

Chronic postoperative opioid use is defined as continued opioid consumption greater than 3-months after surgery [13]. The causes of postoperative chronic opioid use are complex and multifactorial. The magnitude of surgery may not necessarily be the strongest predictive factor for the development of chronic postoperative opioid use [13, 14]. Opioid dependency following orthopedic procedures is well described in the literature, yet little is known about opioid dependency following major head and neck reconstructive surgery [15-18].

Major head and neck cancer resections with free flap reconstruction are lengthy and complex procedures and patients often require nasogastric and tracheotomy tubes. These interventions have a major impact on postoperative patient comfort and can make pain management challenging. In most head and neck centers, narcotic analgesics form a major component of postoperative pain control regimens $[19,20]$. In our center, similar to others, most patients are managed with intravenous patient-controlled analgesia (PCA) for the first five postoperative days and subsequently switched to a combination of narcotic and non-narcotic analgesics.
Pain management following major head and neck surgery therefore represents a complex challenge, wherein opioids have traditionally been a mainstay in management [12]. Little is known about the prevalence of chronic opioid use in this patient population. The aim of this study, therefore, is to determine the prevalence of, and risk factors contributing to, chronic postoperative opioid use following head and neck surgery with freeflap reconstruction.

\section{Methods \\ Patient selection}

We performed a retrospective chart review at a tertiary, academic head and neck surgical oncology program (University of Calgary, Calgary, Alberta, Canada), on all adults (age $\geq 18$ years) undergoing primary head and neck surgical resection with free-flap reconstruction from January 2008 - December 2015. Eligible patients met the following criteria: age $\geq 18$ years old undergoing primary surgical resection with free-flap reconstruction, residents of Alberta, Canada, and patients who survived greater than 1 year following hospital discharge, no recurrence within 1 year of surgery, a second primary malignancy or documented metastases within the first postoperative year. Exclusion criteria included: patients undergoing surgery for recurrence, age $<18$ years old, and patients who were not Alberta residents. NonAlberta residents were excluded as their pharmacy information was not readily available. Figure 1 is a Consolidated Standards of Reporting Trials (CONSORT) diagram describing the cohort.

\section{Data collection}

Data extracted from Otobase ${ }^{\mathrm{Tm}}$ included patient demographics, prior tobacco and alcohol use (dichotomized into never/ever), clinical stage, pathological stage, surgical details, and adjuvant treatment. We collected medication data from the Provincial Pharmacy Information Network (PPIN) that included the following information: drugs prescribed, date dispensed, quantity supplied, unit of measure, days supplied per script, DIN, oral morphine equivalents (OME (mg)), and prescriber information. Preoperative opioid use was defined as those who had filled at least one opioid prescription between 31 days and 12-months preoperatively. All drugs classified as opioids were included in the analysis (in descending order of prevalence: codeine, hydromorphone, morphine, oxycodone, fentanyl, tramadol, buprenophrine, meperidine, and tapentadol). Chronic opioid use was defined as filling an opioid prescription more than 90 days after surgery [13]. Data was also collected on patients receiving ongoing opioid prescriptions greater than 12-months postoperatively. The primary outcomes of the study included the prevalence of opioid use at 3- and 12-months 


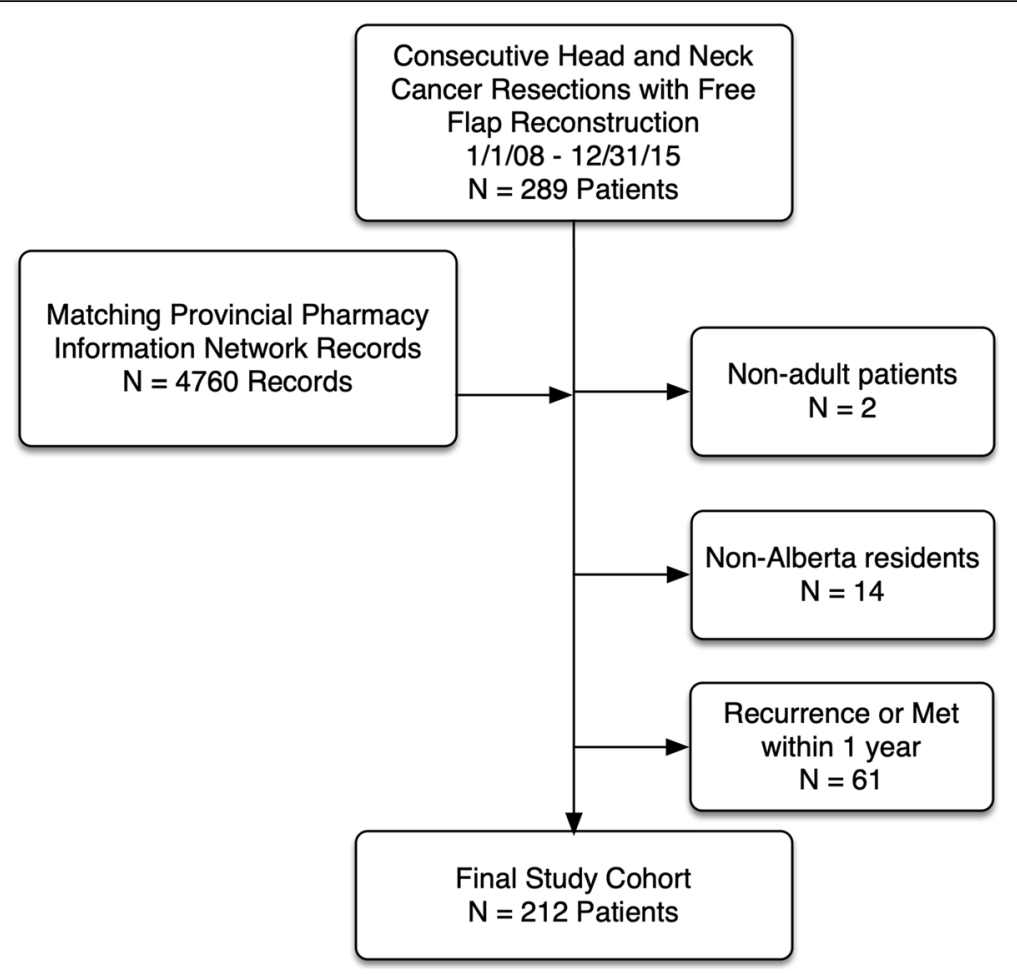

Fig. 1 Study CONSORT diagram

postoperatively. Secondary outcomes of the study were factors associated with chronic postoperative opioid use through univariate and multivariate analysis, and the number of prescribing physicians.

\section{Statistical analysis}

Categorical data were analyzed using a chi-square or Fisher's exact test, as appropriate. Continuous data were compared using appropriate parametric or nonparametric analyses. Variables of interest for regression modelling were included in a series of univariate probes. Univariate analyses achieving $p$-values $\leq 0.2$ were included in the multivariate models. All statistical analyses were performed using Stata 16.0 (StataCorp LP, College Station, Tx). Two-sided tests were used to analyze all data. A $p$-value of $\leq 0.05$ was considered significant.

\section{Ethical approval}

The authors used A Project Ethics Community Consensus Initiative (ARECCI) framework to assess for and mitigate ethical risks, including the ARECCI Ethics Screening Tool and the ARECCI Ethics Guidelines. The project was deemed a quality improvement initiative with a minimal risk $($ ARECCI score $=2)[21]$.

\section{Results}

The clinical characteristics of the cohort $(n=212)$ are shown in Table 1 . The mean age overall was 61 years with a range of 19.5-89.8 years. Prior alcohol use was observed in $145(68 \%)$ patients, and prior tobacco use was observed in 148 (70\%) patients. Eighty-five (40\%) patients were classified as preoperative opioid users. The majority of patients presented with Stage IV disease (108 patients $(51 \%))$. The most common primary site was the oral cavity (164 patients (77\%)). One hundred and ninety-eight (93\%) patients received either a soft tissue or osseous free-flap and 14 patients (7\%) were reconstructed with both a soft tissue and osseous free-flap. All patients underwent primary surgical resection and 120 (57\%) were treated with adjuvant therapy.

Chronic opioid use at 3- and 12-months postoperatively was observed in 136 (64\%) and 116 (55\%) patients, respectively (Table 2 ). Eighty-five patients $(40 \%)$ used opioids preoperatively and, of those, $70(82 \%)$ and 63 (74\%) patients continued to use opioids at 3- and 12months postoperatively, respectively. Pre-operative opioid use was significantly related to 3 - and 12-month post-operative opioid use $(p<0.0001)$.

Table 3 describes the clinical characteristics of chronic opioid users at 3- and 12-months postoperatively. There was a higher proportion of oral cancer in the 3-month chronic opioid use group ( $p=0.03)$.

In univariate logistic regression (Table 4), patients younger than 40 years of age were less likely to continue using opioids at 3 - and 12-months postoperatively (OR $0.25,95 \%$ CI [0.09-0.69), $p<0.007$; OR 0.29, 95\% CI 
Table 1 Patient demographics and clinical characteristics

\begin{tabular}{|c|c|c|c|}
\hline \multirow{2}{*}{$\begin{array}{l}\text { Clinical } \\
\text { Characteristic }\end{array}$} & \multicolumn{3}{|l|}{ Patients $N=212(\%)$} \\
\hline & Preoperative Opioid-Naïve & Preoperative Opioid Use & $p$ value \\
\hline Total & $n=127(60 \%)$ & $n=85(40 \%)$ & \\
\hline Gender & & & 0.046 \\
\hline Male & $96(76 \%)$ & $53(62 \%)$ & \\
\hline Female & $31(24 \%)$ & $32(38 \%)$ & \\
\hline Age (years) & & & 0.8 \\
\hline Mean [SD] & $61.2[13.81]$ & $60.6[12.66]$ & \\
\hline Range & $19.5-89.8$ & $23.4-86.6$ & \\
\hline \multicolumn{4}{|l|}{ Social Habits } \\
\hline Prior Tobacco & $89(70 \%)$ & $59(69 \%)$ & 1.0 \\
\hline Prior Alcohol & $87(69 \%)$ & $58(68 \%)$ & 0.8 \\
\hline Clinical Stage & & & 0.05 \\
\hline In Situ (Stage 0) & $2(2 \%)$ & $1(1 \%)$ & \\
\hline । & $11(9 \%)$ & $15(18 \%)$ & \\
\hline$\|$ & $26(20 \%)$ & $13(15 \%)$ & \\
\hline III & $15(12 \%)$ & $13(15 \%)$ & \\
\hline IV & $65(51 \%)$ & $43(51 \%)$ & \\
\hline Other & $8(6 \%)$ & $0(0 \%)$ & \\
\hline Primary Tumour Location & & & 0.04 \\
\hline Oral Cavity & $102(80 \%)$ & $62(73 \%)$ & \\
\hline Salivary Gland & $4(3 \%)$ & $8(9 \%)$ & \\
\hline Paranasal Sinus & $4(3 \%)$ & $8(9 \%)$ & \\
\hline Other & $17(13 \%)$ & $7(8 \%)$ & \\
\hline Free Flap & & & 1.0 \\
\hline Soft Tissue & 95 (75\%) & $64(75 \%)$ & \\
\hline Bone & $23(18 \%)$ & $16(19 \%)$ & \\
\hline Soft Tissue + bone & $9(7 \%)$ & $5(6 \%)$ & \\
\hline Treatment & & & 0.6 \\
\hline Surgery Alone & $53(42 \%)$ & $39(46 \%)$ & \\
\hline Surgery + Adjuvant & $74(58 \%)$ & $46(54 \%)$ & \\
\hline
\end{tabular}

Table 2 Proportion of patients with chronic postoperative opioid use

\begin{tabular}{|c|c|c|c|c|}
\hline & \multicolumn{4}{|c|}{$3 \mathrm{~m}+$ Chronic Postoperative Opioid Use } \\
\hline & Yes & No & Total & $p$ value \\
\hline Naïve & 66 & 61 & 127 & \\
\hline Non-naïve & 70 & 15 & 85 & \\
\hline \multirow[t]{3}{*}{ Total } & 136 & 76 & 212 & $p<0.0001$ \\
\hline & \multicolumn{4}{|c|}{$12 \mathrm{~m}+$ Chronic Postoperative Opioid Use } \\
\hline & Yes & No & Total & $p$ value \\
\hline Naïve & 53 & 74 & 127 & \\
\hline Non-naïve & 63 & 22 & 85 & \\
\hline Total & 116 & 96 & 212 & $p<0.0001$ \\
\hline
\end{tabular}

[0.10-0.84], $p=0.02$, respectively). Tobacco users were more likely to demonstrate chronic opioid use at 3months and 12-months postoperatively versus nontobacco users (OR 2.52, 95\% CI [1.34-4.76], $p=0.004$; OR $1.8795 \%$ CI [1.01-3.48] $p=0.048$, respectively). Advanced pathologic $\mathrm{T}$-stage was significantly associated with 3-month postoperative chronic opioid use (OR 2.27, 95\% CI [1.24-4.15], $p=0.008$ ). Patients undergoing both surgery and adjuvant therapy were nearly three times as likely to continue using opioids 3 -months postoperatively (OR 2.52, 95\% CI [1.42-4.48] $p<0.002$ ) compared to patients undergoing surgery alone. Preoperative opioid use was the strongest predictor of postoperative use at both 3- and 12-months postoperatively (OR 4.31, 95\% CI [2.24-8.32], $p<0.0001$; OR 4.00, 95\% CI [2.19-7.29], $p=0.0001$, respectively). 
Table 3 Clinical characteristics of patients using chronic postoperative opioids

\begin{tabular}{|c|c|c|c|c|c|c|}
\hline \multirow[t]{2}{*}{ Clinical Characteristic } & \multicolumn{3}{|c|}{$3 \mathrm{~m}+$ Chronic Postoperative Opioid Use $(N=136)$} & \multicolumn{3}{|c|}{$12 \mathrm{~m}+$ Chronic Postoperative Opioid Use $(N=116)$} \\
\hline & Naïve $N=66$ (\%) & Non-Naïve $N=70$ (\%) & $p$ value & Naïve $N=53$ (\%) & Non-Naïve $N=63(\%)$ & $p$ value \\
\hline Gender & & & 0.3 & & & 0.7 \\
\hline Male & $44(63 \%)$ & 47 (71\%) & & $38(72 \%)$ & $42(67 \%)$ & \\
\hline Female & $26(37 \%)$ & 19 (29\%) & & $15(28 \%)$ & $21(33 \%)$ & \\
\hline Age (years) & & & 0.7 & & & 0.6 \\
\hline Mean [SD] & $62.3[12.34]$ & $61.6[10.79]$ & & $62.7[12.23]$ & $61.6[10.93]$ & \\
\hline Range & $31.4-88.2$ & $23.4-82.0$ & & $31.8-88.2$ & $23.4-82.0$ & \\
\hline \multicolumn{7}{|l|}{ Social Habits } \\
\hline Prior Tobacco & $53(80 \%)$ & $53(76 \%)$ & 0.6 & $43(81 \%)$ & $46(73 \%)$ & 0.4 \\
\hline Prior Alcohol & 49 (74\%) & 49 (70\%) & 0.3 & $39(74 \%)$ & $43(68 \%)$ & 0.5 \\
\hline Clinical Stage & & & 0.08 & & & 0.2 \\
\hline In Situ (Stage 0) & $0(0 \%)$ & $1(1 \%)$ & & $0(0 \%)$ & $1(2 \%)$ & \\
\hline I & $7(11 \%)$ & $13(19 \%)$ & & $6(11 \%)$ & $13(21 \%)$ & \\
\hline$\|$ & $14(21 \%)$ & $8(11 \%)$ & & $12(25 \%)$ & $8(13 \%)$ & \\
\hline III & $4(6 \%)$ & $11(16 \%)$ & & $3(6 \%)$ & $7(11 \%)$ & \\
\hline IV & $41(62 \%)$ & $37(53 \%)$ & & 31 (59\%) & $34(54 \%)$ & \\
\hline Primary Tumour Location & & & 0.03 & & & 0.06 \\
\hline Oral Cavity & 59 (89\%) & $48(69 \%)$ & & 47 (89\%) & $43(68 \%)$ & \\
\hline Salivary Gland & $2(3 \%)$ & $7(10 \%)$ & & $1(2 \%)$ & $7(11 \%)$ & \\
\hline Paranasal Sinus & $2(3 \%)$ & $8(11 \%)$ & & $2(4 \%)$ & $7(11 \%)$ & \\
\hline Other & $3(5 \%)$ & $7(10 \%)$ & & $3(6 \%)$ & $6(10 \%)$ & \\
\hline Free Flap & & & 1 & & & 0.9 \\
\hline Soft Tissue & 49 (74\%) & $52(74 \%)$ & & 41 (77\%) & $47(75 \%)$ & \\
\hline Bone & $13(20 \%)$ & $14(20 \%)$ & & $10(19 \%)$ & $13(21 \%)$ & \\
\hline Soft Tissue + bone & $4(6 \%)$ & $4(6 \%)$ & & $2(4 \%)$ & $3(5 \%)$ & \\
\hline Treatment & & & 0.2 & & & 0.4 \\
\hline Surgery Alone & 19 (29\%) & $29(41 \%)$ & & 19 (36\%) & $28(44 \%)$ & \\
\hline Surgery + Adjuvant & 47 (71\%) & 41 (59\%) & & $34(64 \%)$ & $35(56 \%)$ & \\
\hline
\end{tabular}

Multivariable logistic regression (Table 4) revealed that preoperative opioid use was associated with postoperative opioid use at both 3- and 12-months postoperatively (OR 4.02, 95\% CI [1.85-8.72], $\mathrm{p}<0.0001$; OR 2.34, 95\% CI [1.15-4.74], $\mathrm{p}<0.0001$, respectively). A history of tobacco use was also independently associated with chronic postoperative opioid use at 3-months and 12months after surgery (OR 2.80, 95\% CI [1.23-6.38], $p=$ 0.014; OR 2.34 95\% CI [1.15-4.74], $p=0.019$ ). Treatment with surgery and adjuvant therapy was independently associated with chronic postoperative opioid use at 3 -months only (OR 2.23, 95\% CI [1.03-4.82], $p=0.042$ ).

Patients who were chronic opioid users at 12 -months postoperatively had a significantly higher number of physicians prescribing opioids compared to patients who were not chronic opioid users. In chronic users, the mean number of prescribers at 3 - and 12 months postoperative was $2.6(p=0.08)$ and $2.8(p<0.0027)$, respectively. The mean number of prescribers for patients who were no longer using opioids at 3 - and 12months was 1.7 for both time points.

\section{Discussion}

This study examined the prevalence of chronic opioid use following primary head and neck cancer surgery with free-flap reconstruction. We found a high proportion of patients using opioids at 3- and 12-months postoperatively (67 and $48 \%$, respectively). In an unadjusted analysis, chronic postoperative opioid use was strongly associated with preoperative opioid use, a history of tobacco use, advanced pathologic T-stage, and postoperative adjuvant therapy. Multivariate analysis revealed that preoperative opioid use and multimodality treatment were significantly associated with chronic postoperative opioid use. 
Table 4 Univariate and Multivariate logistic regression analysis of factors associated with chronic postoperative opioid use

\begin{tabular}{|c|c|c|c|c|}
\hline \multirow[t]{2}{*}{ Clinical Characteristic } & \multicolumn{2}{|c|}{$3 \mathrm{~m}+$ Persistent Opioid Use } & \multicolumn{2}{|c|}{$12 \mathrm{~m}$ + Persistent Opioid Use } \\
\hline & Odds Ratio $[95 \% \mathrm{Cl}]$ & $p$-value & Odds Ratio $[95 \% \mathrm{Cl}]$ & $p$-value \\
\hline \multicolumn{5}{|l|}{ Univariate Probes } \\
\hline Gender (Ref: Female) & $1.59[0.84-3.02]$ & 0.152 & $1.15[0.64-2.08]$ & 0.6 \\
\hline Age (years) (centered at mean) & $1.01[0.99-1.04]$ & 0.153 & $1.01[0.99-1.04]$ & 0.168 \\
\hline$\geq 65$ & $1.04[0.59-1.85]$ & 0.9 & $1.04[0.60-1.81]$ & 0.9 \\
\hline $55-64$ & $1.34[0.72-2.50]$ & 0.4 & $1.44[0.79-2.61]$ & 0.2 \\
\hline $40-54$ & $1.31[0.65-2.65]$ & 0.5 & $1.04[0.54-2.02]$ & 0.9 \\
\hline$<40$ & $0.25[0.09-0.69]$ & 0.007 & $0.29[0.10-0.84]$ & 0.022 \\
\hline Pre-operative opioid use & $4.31[2.24-8.32]$ & $<0.0001$ & $4.00[2.19-7.29]$ & $<0.0001$ \\
\hline \multicolumn{5}{|l|}{ Social Habits } \\
\hline Prior Tobacco & $2.52[1.34-4.76]$ & 0.004 & $1.87[1.01-3.48]$ & 0.048 \\
\hline Prior Alcohol & $1.24[0.61-2.51]$ & 0.6 & $1.13[0.57-2.24]$ & 0.7 \\
\hline Advanced pathologic T-stage (T3/4) & $2.27[1.24-4.15]$ & 0.008 & $1.21[0.70-2.12]$ & 0.5 \\
\hline \multicolumn{5}{|c|}{ Primary Tumour Location (ref: Oral Cavity) } \\
\hline Salivary Gland & $1.60[0.42-6.14]$ & 0.5 & $1.64[0.48-5.68]$ & 0.4 \\
\hline Paranasal Sinus & $2.66[0.56-12.57]$ & 0.2 & $2.47[0.64-9.44]$ & 0.187 \\
\hline Other & $0.38[0.16-0.91]$ & 0.03 & $0.49[0.20-1.19]$ & 0.1 \\
\hline \multicolumn{5}{|l|}{ Free Flap (Ref: Soft Tissue) } \\
\hline Bone & $1.29[0.61-2.74]$ & 0.5 & $1.15[0.57-2.36]$ & 0.7 \\
\hline Soft Tissue + Bone & $0.77[0.25-2.32]$ & 0.6 & $0.45[0.14-1.40]$ & 0.167 \\
\hline \multicolumn{5}{|l|}{ Treatment (ref: Sx Alone) } \\
\hline Sx + Adjuvant & $2.52[1.42-4.48]$ & 0.002 & $1.30[0.75-2.24]$ & 0.4 \\
\hline \multicolumn{5}{|l|}{ Multivariate Model } \\
\hline Gender (Ref: Female) & $2.15[0.92-5.01]$ & 0.08 & - & - \\
\hline Age (years) (centered at mean) & $0.99[0.96-1.03]$ & 0.7 & $1.00[0.97-1.03]$ & 0.8 \\
\hline$<40$ & $0.25[0.04-1.35]$ & 0.1 & $0.37[0.08-1.76]$ & 0.2 \\
\hline Pre-operative opioid use & $4.02[1.85-8.72]$ & $<0.0001$ & $2.34[1.15-4.74]$ & $<0.0001$ \\
\hline \multicolumn{5}{|l|}{ Social Habits } \\
\hline Prior Tobacco & $2.80[1.23-6.38]$ & 0.014 & $2.34[1.15-4.74]$ & 0.019 \\
\hline Advanced pathologic T-stage (T3/4) & $1.70[0.79-3.69]$ & 0.2 & - & - \\
\hline \multicolumn{5}{|c|}{ Primary Tumour Location (ref: Oral Cavity) } \\
\hline Salivary Gland & $0.63[0.14-2.95]$ & 0.6 & $1.09[0.28-4.35]$ & 0.9 \\
\hline Paranasal Sinus & $1.91[0.27-13.42]$ & 0.5 & $1.99[0.42-9.36]$ & 0.4 \\
\hline Other & $0.37[0.12-1.15]$ & 0.09 & $0.44[0.15-1.28]$ & 0.1 \\
\hline \multicolumn{5}{|l|}{ Free Flap (Ref: Soft Tissue) } \\
\hline Bone & - & - & $1.25[0.56-2.80]$ & 0.6 \\
\hline Soft Tissue + Bone & - & - & $0.33[0.09-1.19]$ & 0.09 \\
\hline \multicolumn{5}{|l|}{ Treatment (ref: Sx Alone) } \\
\hline Sx + Adjuvant & $2.23[1.03-4.82]$ & 0.042 & - & - \\
\hline
\end{tabular}

A recent retrospective study by Smith et al. investigated prolonged opioid use $(6$ months after treatment completion) in head and neck patients undergoing curative-intent radiation therapy (RT). These authors found that RT given in an adjuvant setting was associated with a lower probability of opioid use at 6 months after completion of RT. Our study found that adjuvant therapy was associated with increased opioid use at 3 months but this association was no longer seen at 12 months after treatment [22]. 
There is limited research evaluating the prevalence of chronic postoperative opioid use in the head and neck cancer population. Pang et al. studied the prevalence of chronic postoperative opioid use at 3-months following primary surgical resection for oral cavity cancer and $41 \%$ of patients continued to use opioids at 3-months postoperatively with $82 \%$ of the patients citing head and neck cancer pain as the primary reason for continued opioid use [18]. Our study results are slightly higher than previously reported results, likely secondary to our cohort's clinical characteristics. A high proportion of our patient population $(47 \%)$ had a pT-stage of T3 or higher, versus $34 \%$ of patients reported by Pang et al. Furthermore, our study demonstrated advanced pathologic $\mathrm{T}$-stage to be significantly associated with chronic postoperative opioid use at 3 months postoperatively.

Our study demonstrated preoperative opioid use to be the strongest predictor of opioid use at 3 and 12-months postoperatively, consistent with previously reported results across all surgical specialties [13]. Multiple studies have demonstrated poor pain control in the head and neck cancer population despite heavy utilization of opioids. This suggests that opioid use alone is an ineffective strategy in head and neck cancer postoperative pain management [13, 18, 23]. However, chronic postoperative opioid use is complex and the risk of developing postoperative chronic opioid use is not solely related to the degree of postoperative pain. Brummett et al. compared the incidence of new chronic opioid use in patients undergoing major versus minor surgical procedures and found the incidence of chronic postoperative opioid use did not differ between major and minor surgical procedures [14]. Mudumbaje et al. studied a variety of surgical procedures and reported that prior opioid use was the best predictor of postoperative opioid use, independent of surgical procedure [24].

Our study also found that tobacco and adjuvant treatment were risk factors for chronic postoperative opioid use, which is consistent with previous reports [13]. We also found that patients younger than age 40 were less likely to become chronic opioid users. This finding conflicts with studies that show younger age is more commonly associated with chronic postoperative opioid use [13]. However, the definition of younger versus older age is inconsistent in the literature. Several factors unrelated to pain, such as physicians' prescribing patterns, may also play a role in the development of chronic postoperative opioid use in our cohort. Patients who continued to use opioids at 3- and 12-months postoperatively had a significantly higher number of prescribers compared to patients who were no longer using opioids. This is an interesting finding that suggests patients using opioids chronically may be seeking treatment from multiple providers.
Despite the frequent use of opioid-based analgesics, pain management is ineffective in over $50 \%$ of cancer patients and the highest pain prevalence is found in patients with head and neck cancer (70\%) [25]. Our centre recently evaluated the effectiveness of postoperative pain management in a head and neck cancer surgery population. We found that $85 \%$ of our patients, managed primarily with opioids, experienced ineffective pain control during some portion of their hospital stay [12]. These data suggest that current approaches to postoperative pain management in head and neck surgery are not optimal and the risks of opioid use may outweigh the potential benefits.

Multimodal analgesia is an effective method of controlling postoperative pain and can help reduce the use of opioids and subsequent adverse events such as the development of chronic postoperative opioid use [26, 27]. Recently Eggerstedt et al. demonstrated that multimodal analgesia significantly improved postoperative pain compared to narcotics alone in head and neck cancer surgery with free flap reconstruction, while also demonstrating a significant reduction in narcotic consumption in the immediate postoperative period and at discharge [28]. Appropriate preoperative counselling of patients to manage expectations pertaining to the expected postoperative pain experience is also an essential component of effective postoperative pain management.

Our study confirms the finding, as in other surgical populations, that preoperative opioid use strongly predicts chronic postoperative opioid use [13]. A novel finding arising from our study is the association between multimodality head and neck cancer treatment and chronic postoperative opioid use. Adjuvant therapy was only associated with opioid use at 3-months and not 12months and therefore we believe the adjuvant treatment had an impact on pain. While patients are undergoing adjuvant treatment it is important to assess and treat their pain effectively, while also minimizing the risk of chronic opioid use. We believe this information will help clinicians identify patients at higher risk of chronic postoperative opioid use and perhaps implement strategies that will reduce the risk of ongoing opioid use. At our regional cancer centre, the data from this study has helped to triage those high-risk patients towards earlier visits with our acute and chronic pain service, so as to mitigate chronic opioid use at an earlier stage in the patients' treatment.

The present study neither explored reasons for persistent opioid use nor the amount of opioids consumed before or after surgery. This may be an important question that could be addressed through future research but was not the primary focus of the current work. Our study is also limited by its analysis of opioid-dispensing patterns only, with the assumption that this corresponds to 
consumption patterns; in some instances, this may not be true. However, patients filling an opioid prescription are most likely using the prescribed drug. Finally, we did not adjust the followup time for patients who received adjuvant therapy because our data show that adjuvant and non-adjuvant patients were not different in their opoid consumption at 12 months. This study is strengthened by its use of prospectively collected clinical data and the comprehensive Provincial Pharmacy Information Network (PPIN) used to capture drug-dispensing information. Such data are highly reliable, and we are confident in its accuracy and reliability.

\section{Conclusions}

In conclusion, patients undergoing major head and neck surgery are at risk for developing chronic postoperative opioid use. Our study identified several risk factors that are associated with chronic opioid use, primarily preoperative opioid use and multimodality treatment. The underlying mechanism for chronic postoperative opioid use is likely multifactorial. With this information we believe clinicians will become more aware of patients at a potentially higher risk of continued opioid use postoperatively and consider implementing strategies to help reduce peri-operative and chronic postoperative opioid use.

\section{Abbreviations}

PPIN: Provincial Pharmacy Information Network; OME: Oral Morphine Equivalents; ARECCl: A Project Ethics Community Consensus Initiative CONSORT: Consolidated Standards of Reporting Trials

\section{Acknowledgements}

The authors gratefully acknowledge Dr. Marc Coltrera, University of Washington, Seattle, USA for his prior and ongoing work in developing and maintaining Otobase as an important tool for head and neck clinical research.

\section{Authors' contributions}

$\mathrm{AH}$ : conception and design of study, acquisition of data, data analysis, draft, revision and final approval of manuscript. AR: conception and design of study, revision and final approval of manuscript. SN: acquisition of data, data analysis, revision and final approval of manuscript. $\mathrm{RH}$ : data analysis, revision and final approval of manuscript. SC: data analysis, revision and final approval of manuscript. TWM: data analysis, revision and final approval of manuscript. JD: conception and design of study, acquisition of data, data analysis, draft, revision and final approval of manuscript.

\section{Funding}

Not applicable.

\section{Availability of data and materials}

The datasets used and/or analysed during the current study are available from the corresponding author on reasonable request.

\section{Declarations}

\section{Ethics approval and consent to participate}

The authors used A Project Ethics Community Consensus Initiative (ARECCI) framework to assess for and mitigate ethical risks, including the ARECCI Ethics Screening Tool and the ARECCI Ethics Guidelines. The project was deemed a quality improvement initiative with a minimal risk (ARECCI score $=2$ ).
Consent for publication

Not applicable.

\section{Competing interests}

The authors declare that they have no competing interests.

Received: 2 May 2020 Accepted: 8 March 2021

Published online: 23 April 2021

\section{References}

1. Manchikanti L, Helm S 2nd, Fellows B, Janata JW, Pampati V, Grider JS, et al. Opioid epidemic in the United States. Pain Physician. 2012 Jul;15(3 Suppl): ES9-38.

2. Canadian Institute for Health Information. Types of Opioid Harms in Canadian Hospitals: Comparing Canada and Australia. Ottawa.

3. Compton WM, Jones CM, Baldwin GT. Relationship between Nonmedical Prescription-Opioid Use and Heroin Use. N Engl J Med. 2016;374(2):154-63 Longo DL, editor. Massachusetts Medical Society.

4. Maxwell JC, et al. Drug Alcohol Rev. 2011;30(3):264-70 John Wiley \& Sons, Ltd (10.1111).

5. Reddy A, de la Cruz M, Rodriguez EM, Thames J, Wu J, Chisholm G, et al. Patterns of storage, use, and disposal of opioids among cancer outpatients. Oncologist. 2014;19(7):780-5 AlphaMed Press.

6. Alexander GC, Frattaroli S, Gielen AC. The prescription opioid epidemic: an evidence-based approach; 2015.

7. Quality improvement guidelines for the treatment of acute pain and cancer pain. American pain society quality of care committee. JAMA. 1995;274(23): 1874-80.

8. Practice guidelines for acute pain management in the perioperative setting. A report by the American Society of Anesthesiologists Task Force on Pain Management, Acute Pain Section. Anesthesiology. 1995;82:1071-81.

9. Tan M, Law LS-C, Gan TJ. Optimizing pain management to facilitate enhanced recovery after surgery pathways. Can J Anaesth. 2012;62(2):20318 Springer US

10. Oderda GM, Evans RS, Lloyd J, Lipman A, Chen C, Ashburn M, et al. Cost of opioid-related adverse drug events in surgical patients. J Pain Symptom Manag. 2003;25(3):276-83.

11. Clarke H, Soneji N, Ko DT, Yun L, Wijeysundera DN. Rates and risk factors for prolonged opioid use after major surgery: population based cohort study. Bmj. 2014;348:g1251.

12. Hinther A, Nakoneshny SC, Chandarana SP, Wayne Matthews T, Dort JC. Efficacy of postoperative pain management in head and neck cancer patients. J Otolaryngol Head Neck Surg. 2018;47(1):29-6 2017 46:1. BioMed Central.

13. Hinther A, Abdel-Rahman O, Cheung WY, Quan ML, Dort JC. Chronic postoperative opioid use: a systematic review. World J Surg. 2019;43(9): 2164-74 Springer International Publishing.

14. Brummett CM, Waljee JF, Goesling J, Moser S, Lin P, Englesbe MJ, et al. New persistent opioid use after minor and major surgical procedures in US adults. JAMA Surg. 2017;152(6):e170504.

15. Bedard NA, Pugely AJ, Westermann RW, Duchman KR, Glass NA, Callaghan JJ. Opioid use after Total knee Arthroplasty: trends and risk factors for prolonged use. J Arthroplast. 2017;32(8):2390-4.

16. Dabbagh Al Z, Jansson KA, Stiller CO, Montgomery S, Weiss RJ. Long-term pattern of opioid prescriptions after femoral shaft fractures. Acta Anaesthesiol Scand. 2016;60(5):634-41.

17. Inacio MC, Pratt NL, Roughead EE, Paxton EW, Graves SE. Opioid use after total hip arthroplasty surgery is associated with revision surgery. BMC Musculoskelet Disord. 2016;17:122.

18. Pang J, Tringale KR, Tapia VJ, Moss WJ, May ME, Furnish T, et al. Chronic opioid use following surgery for Oral cavity Cancer. JAMA Otolaryngol Head Neck Surg. 2017;143(12):1187-94.

19. Bianchini C, Maldotti F, Crema L, Malagò M, Ciorba A. Pain in head and neck cancer: prevalence and possible predictive factors. J BUON. 2014; 19(3):592-7

20. Bianchini C, Malagò M, Crema L, Aimoni C, Matarazzo T, Bortolazzi S, et al. Post-operative pain management in head and neck cancer patients: predictive factors and efficacy of therapy. Acta Otorhinolaryngol Ital. 2016; 36(2):91-6.

21. cci-ethics-guideline-tool AIA-EPA, 2018. ARECCI Ethics Guideline Tool.(2017). 
22. Smith WH, Luskin I, Resende Salgado L, Scarborough BM, Lin J-Y, Özbek U, et al. Risk of prolonged opioid use among cancer patients undergoing curative intent radiation therapy for head and neck malignancies. Oral Oncol. 2019:92:1-5.

23. Orgill R, Krempl GA, Medina JE. Acute pain management following laryngectomy. Arch Otolaryngol Head Neck Surg. 2002;128(7):829-32 American Medical Association.

24. Mudumbai SC, Oliva EM, Lewis ET, Trafton J, Posner D, Mariano ER, et al. Time-to-cessation of postoperative opioids: a population-level analysis of the veterans affairs health care system. Pain Med. 2016;17(9):1732-43.

25. van den Beuken-van Everdingen MHJ, de Rijke JM, Kessels AG, Schouten HC, van Kleef M, Patijn J. Prevalence of pain in patients with cancer: a systematic review of the past 40 years. Ann Oncol. 2007 Sep;18(9):1437-49.

26. Halawi MJ, Grant SA, Bolognesi MP. Multimodal analgesia for Total joint Arthroplasty. Orthopedics. 2015;38(7):e616-25 SLACK Incorporated.

27. Wick EC, Grant MC, Wu CL. Postoperative multimodal analgesia pain management with nonopioid analgesics and techniques: a review. JAMA Surg. 2017;152(7):691-7.

28. Eggerstedt M, Stenson KM, Ramirez EA, Kuhar HN, Jandali DB, Vaughan D, et al. Association of Perioperative Opioid-Sparing Multimodal Analgesia with Narcotic use and Pain Control after Head and neck free flap reconstruction. JAMA Facial Plast Surg. 2019;21(5):446.

\section{Publisher's Note}

Springer Nature remains neutral with regard to jurisdictional claims in published maps and institutional affiliations.

Ready to submit your research? Choose BMC and benefit from:

- fast, convenient online submission

- thorough peer review by experienced researchers in your field

- rapid publication on acceptance

- support for research data, including large and complex data types

- gold Open Access which fosters wider collaboration and increased citations

- maximum visibility for your research: over $100 \mathrm{M}$ website views per year

At $\mathrm{BMC}$, research is always in progress.

Learn more biomedcentral.com/submissions 